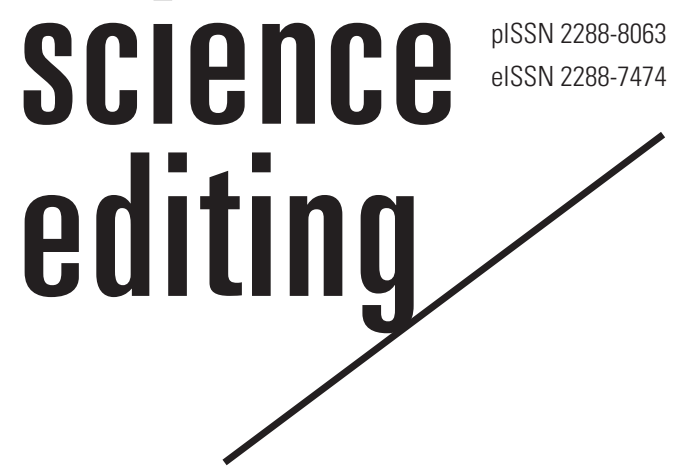

\title{
The rise of preprints and their value in social sciences and humanities
}

\author{
Quan-Hoang Vuong ${ }^{1,23}$
}

${ }^{1}$ Centre Emile Bernheim, Université Libre de Bruxelles, Belgium; ${ }^{2}$ Scientific Council on Basic Research in the Social Sciences and Humanities, National Foundation for Science and Technology Development (NAFOSTED), Hanoi, Vietnam; ${ }^{3}$ Centre for Interdisciplinary Social Research, Phenikaa University, Hanoi, Vietnam

\section{Introduction}

In this short essay, I describe the experience I have gained from my own 'experiments', so to speak, on the actual value of non-peer-reviewed preprints in social sciences and humanities and whether they are beneficial for their authors. To present my ideas about the possible value of preprints as a means of (somewhat primitive) scientific publishing, the article will start with three cases, in which my preprints turned out to be useful and citable. Then, it proceeds to draw some short but worthwhile lessons for prospective authors.

\section{The First Case: an Old Manuscript Deposited to a Frequently Cited Preprint Server}

In one case, following the introduction of the preprint system at the Centre Emile Bernheim, Universite Libre de Bruxelles, I sent an old unpublished manuscript to the administrator to post it online (https://difusion.ulb.ac.be/vufind/Record/ULB-DIPOT:oai:dipot.ulb.ac.be:2013/14581/ TOC) [1]. I had no expectations whatsoever for its future use, except that people wishing to read it would have a place to find it. One reason for these modest expectations was the fact that the manuscript had been presented at an international conference and its abstract had been published in the conference proceeding.

To my surprise, the paper has since been read and cited by numerous researchers, in master's and doctoral theses [2], journal articles [3], book chapters [4], and other working manuscripts [5].

Received: September 14, 2019

Accepted: October 25, 2019

\section{Correspondence to \\ Quan-Hoang Vuong \\ hoang.vuongquan@phenikaa-uni. \\ edu.vn}

ORCID

Quan-Hoang Vuong

https://orcid.org/0000-0003-0790-1576
At that time, preprint servers in social sciences and humanities were not widely used, except among economics research circles, where the SSRN and RePEc systems had been around for 10 years or so. It can be said that I stumbled on the opportunity to do this experiment to obtain some first-hand experience about preprints and their potential value. 


\section{The Second Case: A Manuscript That Was Not Accepted by a Journal, But Was Deposited to a Frequently Cited Preprint Server}

The next experiment occurred in 2014 when I submitted a manuscript to a German journal. Although the reviewers and editors appeared to have liked the manuscript, they did not seem to endorse the innovative approach and what they perceived as strange thinking that I presented in the manuscript and requested me to make too many changes. I faced a dilemma. If I had moved forward with publishing the paper, it would have contained a completely different set of ideas due to the removal of all innovative analyses and 'subjective' assessments. Alternatively, I could keep my ideas in the manuscript; however, the paper would then not be accepted because it would not fit the aims and scope of the journal. Thus, even though it was unfortunate that the German journal's editors and reviewers did not move forward with the publication of my initial ideas, I stumbled on another opportunity to use a preprint server to disseminate my ideas and to stimulate discussion, this time with a clear expectation that it would be distributed, read, and possibly cited. I posted it to IDEAS/ RePEc through the system of Université Libre de Bruxelles (working papers CEB, no. 14-010.RS; https://ideas.repec.org/ p/sol/wpaper/2013-163371.html) [6].

Once again, the experiment did not fail at all. Over the past 5 years, this article has been used by dozens of authors, in many different research studies, including doctoral dissertations [7], master's theses [8], journal articles [9], and book chapters [10]. By this time, preprint servers had become fairly well known, but editors and reviewers were still puzzled about their usage, and sometimes refused to consider a submission just because it had already appeared online as a non-peer-reviewed preprint. An example of this misunderstanding of the nature of preprints is furnished by the story of a the postdoctoral researcher Alison Gerber, who also faced a similar problem because her paper was available on the preprint repository SocArXiv [11]. Another example is provided by the policy of a journal regarding preprints, according to which even though the journal does not strictly forbid preprints, the visibility of authors' information might affect the double-blind review process and reviewers' comments about the paper (the source did not disclose the name of the journal) [12].

\section{The Third Case: A Manuscript Accepted by a Journal after Deposition to a Preprint Server}

By the time of the third case, preprint servers had become widely known, with systems such as Open Science Framework, arXiv, and RePEc being used by hundreds of thousands of academics. Furthermore, our work was also a major one, with a lot of time and effort needed to complete the manuscript. As the senior author of the study, I decided to intentionally and voluntarily submit it to several preprint servers before submitting it to any journal. Why did I decide to take the risk? after all, there were still editorial boards that refused to consider preprints as submissions Simply because I am an advocate for preprint server systems and open science. We posted it to multiple servers: Academia, OSF, SSRN, IDEAS/ RePEc, arXiv, and PhilPapers [13].

Then, we proceeded to submit the manuscript to Palgrave Communications, published on the platform of Nature Publishing Group (NPG). I had a few concerns, as I believed NPG to be a publisher that pioneered numerous innovations in science publishing; therefore, the likelihood that they would consider an online preprint would be high. It turned out that my thinking was correct. NPG had no problem with preprints and even announced that they encourage not just preprints, but also preregistered reports [14].

Therefore, nothing unexpected occurred regarding the use of preprint servers. The real surprise is that although the manuscript was peer-reviewed in a relatively short period of time (roughly three and a half months), its preprint version still received the first citation by an official peer-reviewed article [15], well ahead of the formal publication [16].

\section{Conclusion}

There are different ways to look at the use and value of preprints, and debates continue on whether something belonging to the 'gray literature' like preprints should be formally recognized, or whether preprints would need some 'light' screening before being accepted to go live. For instance, Sheldon has warned that a bad preprint that attracts media attention might lead to confusion in society [17]. However, to maintain a healthy academic ecosystem [18], the following values have been suggested for preprint servers. First, if a research manuscript is not peer-reviewed, that does not necessarily mean that it is not useful or that it is uncitable. Second, sometimes, preprint alternatives can be valuable for preserving the original thinking of an author, which could be distorted when it becomes necessary to appease an unknowledgeable or rigid reviewer. Some authors may also use preprint servers to tell the world about their intention to preserve their free will [19]. Therefore, I suggest that preprints may be a valuable contribution as an open platform to share our raw ideas with a wider audience by allowing authors to share working papers, preprints, postprints, or published papers in an economical manner $[20,21]$. 


\section{Conflict of Interest}

No potential conflict of interest relevant to this article was reported.

\section{Acknowledgments}

This paper was funded by the Vietnam National Foundation for Science and Technology Development (NAFOSTED) under the National Research Grant no. 502.01-2018.19.

\section{References}

1. Farber A, Nguyen VN, Vuong QH. Policy impacts on Vietnam stock markets: a case of anomalies and disequilibria 2000-2006 [Internet]. Brussels: Université Libre de Bruxelles; 2006 [cited 2019 Oct 11]. Available from: https://ideas.repec.org/p/sol/wpaper/06-005.html

2. Tran MA. The influence of macroeconomic announcements into Vietnamese stock market volatility [thesis]. Vaasa: University of Vaasa; 2016.

3. My TN, Truong HH. Herding behavior in an emerging stock market: empirical evidence from Vietnam. Res J Bus Manag 2011;5:51-76.

4. Hachicha N, Amirat A, Bouri A. Herding does not exist or just a measurement problem? A meta-analysis. In: Gunasekaran A, Sandhu M, editors. Handbook on business information systems. Singapore: World Scientific; 2010. p. 817-52.

5. Kallinterakis V. Herding and the thin trading bias in a start-up market: evidence from Vietnam. Durham: University of Durham Business School; 2007. https://doi. org/10.2139/ssrn.1105976

6. Vuong QH. Vietnam's political economy: a discussion on the 1986-2016 period [Internet]. Brussels: Université Libre de Bruxelles; 2014 [cited 2019 Oct 11]. Available from: https://ideas.repec.org/p/sol/wpaper/2013-163371.html

7. Vo MT. Autonomy of public service delivery units in Vietnam: an institutional perspective [dissertation]. Wellington: Victoria University of Wellington; 2018.

8. Nguyen DT. Vietnamese teachers' perspectives regarding task-based approach to vocabulary instruction in secondary school English as a foreign language classrooms [thesis]. Miami, FL: Florida International University; 2018.

9. Hansen A. Driving development? The problems and promises of the car in Vietnam. J Contemp Asia 2016;46:551-69. https://doi.org/10.1080/00472336.2016.1151916

10. Ascher W, Brewer GD, Cheema GS. The evolution of de- velopment thinking. New York, NY: Palgrave Macmillan US; 2016.

11. Flaherty C. Questionable rejection [Internet]. Inside Higher Ed; 2019 [cited 2019 Oct 11]. Available from: https:// www.insidehighered.com/news/2019/08/26/sociologist -says-journal-rejected-her-paper-because-shes-shared-itelsewhere

12. Andrew. Hey, here's a new reason for a journal to reject a paper: it's "annoying" that it's already on a preprint server [Internet]. [place unknown]: Statistical Modeling, Causal Inference, and Social Science; 2018 [cited 2019 Oct 11]. Available from: https://statmodeling.stat.columbia.edu/2018/01/15/ hey-heres-new-reason-journal-reject-paper-annoying-already-preprint-server/

13. Vuong QH, Ho MT, La VP, et al. "Cultural additivity" and how the values and norms of Confucianism, Buddhism, and Taoism co-exist, interact, and influence Vietnamese society: a Bayesian analysis of long-standing folktales, using R and Stan. arXiv 1803.06304 [Preprint]. 2018 [cited 2019 Oct 11]. Available from: https://arxiv.org/abs/1803.06304

14. Mellor D. Promoting reproducibility with registered reports. Nat Hum Behav 2017;1:34.

15. Le TM, Yu N. Ideological and philosophical underpinnings of attitudes toward sexual minorities in Vietnamese society. Sex Cult 2019;23:444-57.

16. Vuong QH, Bui QK, La VP, et al. Cultural additivity: behavioural insights from the interaction of Confucianism, Buddhism, and Taoism in folktales. Palgrave Commun 2018;4:143. https://doi.org/10.1057/s41599-018-0189-2

17. Sheldon T. Preprints could promote confusion and distortion. Nature 2018;559:445. https://doi.org/10.1038/d41586018-05789-4

18. Vuong QH. Breaking barriers in publishing demands a proactive attitude. Nat Hum Behav 2019;3:1034; https:// doi.org/10.1038/s41562-019-0667-6

19. Nasar S, Gruber D. Manifold destiny. The New Yorker [Internet]. 2006 Aug 28 [cited 2019 Oct 11]. Available from: https://www.newyorker.com/magazine/2006/08/28/manifold-destiny

20. Vuong QH. The (ir)rational consideration of the cost of science in transition economies. Nat Hum Behav 2018;2:5. https://doi.org/10.1038/s41562-017-0281-4

21. Ho MT, Nguyen TH, Vuong TT, et al. To walk on the Penrose stairs of science [Internet]. Behavioural \& Social Sciences at Nature Research; 2019 [cited 2019 Oct 12]. Available from: https://socialsciences.nature.com/users/301097ho-manh-toan/posts/54541-to-walk-on-the-penrosestairs-of-science 